\section{Experiments with mathematical models to simulate hepatitis A population dynamics under different levels of endemicity}

\author{
Modelagem matemática para simular a dinâmica \\ populacional da hepatite $A$ de acordo \\ com diferentes níveis de endemicidade
}

\author{
1 Instituto de Ciências \\ Biológicas, Universidade de \\ Pernambuco, Recife, Brasil. \\ 2 Programa de Computação \\ Científica, Fundação \\ Oswaldo Cruz, \\ Rio de Janeiro, Brasil. \\ Correspondence \\ C. T. Codeço \\ Programa de Computação \\ Científica, Fundação \\ Oswaldo Cruz. \\ Av. Brasil 4365, \\ Rio de Janeiro, $R J$ \\ 21045-900, Brasil. \\ codeco@malaria.procc. \\ fiocruz.br
}

\begin{abstract}
Heterogeneous access to sanitation services is a characteristic of communities in Brazil. This heterogeneity leads to different patterns of hepatitis A endemicity: areas with low infection rates have higher probability of outbreaks, and areas with higher infection rates have high prevalence and low risk of outbreaks. Here we develop a mathematical model to study the effect of variable exposure to infection on the epidemiological dynamics of hepatitis A. Differential equations were used to simulate population dynamics and were numerically solved using the software Stella ${ }^{\mathrm{TM}}$. The model uses parameters from serological surveys in the Greater Metropolitan Rio de Janeiro, in areas with different sanitation conditions. Computer simulation experiments show that the range of infection rates observed in these communities are characteristic of high and low levels of hepatitis A endemicity. We also found that the functional relationship between sanitation and exposure to infection is an important component of the model. The analysis of the public health impact of partial sanitation requires a better understanding of this relationship.
\end{abstract}

Hepatitis A; Mathematical Models; Populations Dynamics
Mariana Alves de Guimaraens 1

Cláudia Torres Codeço ${ }^{2}$

\section{Introduction}

Brazil is a very large and heterogeneous country. Szwarcwald et al. 1 describe the existence of two Brazils, one characterized by adequate access to sanitation and health services and another Brazil with poor access to such services. These two Brazils are intertwined on all geographic scales. At the national scale, half of the population has adequate access to sewage disposal, while the other half must dispose of their sewage very rudimentarily. This pattern is repeated on smaller scales. Even in Greater Metropolitan Rio de Janeiro, only $63 \%$ of the population has access to sewage disposal services. Moreover, communities with adequate sanitation services and those with poor access live side by side 2 .

Hepatitis A is a viral disease transmitted from person to person mainly by the fecal-oral route. Worldwide, there are three major patterns of hepatitis A epidemiology ${ }^{3}$. In areas where sanitation is very poor, nearly all children under 9 years old show evidence of prior infection. In these areas, hepatitis A is considered highly endemic, outbreaks rarely occur, and symptomatic hepatitis is uncommon. Since almost all residents become naturally immune to hepatitis A during childhood, hepatitis A in adolescents and adults is not observed. Countries of intermediate disease endemicity, on the other hand, have a relatively large propor- 
tion children and adolescents susceptible to the hepatitis A virus, because part of the population has access to adequate sewage disposal and water supply, which lower the risk of acquiring hepatitis A during childhood. In these areas, there are outbreaks of hepatitis A in adolescent and adults populations, which may represent a significant public health burden because infection is more virulent in this age class. The third pattern is observed in regions of low disease endemicity, where risk of acquiring the infection is very low.

In Latin America and some other areas of the developing world, the epidemiological pattern of hepatitis A is changing from highly endemic to intermediate 4,5 . Infection rates are decreasing in children and increasing in teenagers and adults. This shift is not uniform, however, and varies between rural and urban areas and among social classes. These variations reflect underlying differences in local quality of life. In Brazil, a similar change has been observed. Age at infection has been shifting towards older age groups 6 . Clemens et al. 7 surveyed the hepatitis A seroprevalence in four metropolitan areas of Brazil. In Rio de Janeiro, they found that seropositivity at age 10 is some $50 \%$ in the lower social class and some $28 \%$ in the intermediate plus higher social classes. In Fortaleza, Ceará, more than $90 \%$ of children are seropositive at age 10 in the lower social classes; in the other classes, seroprevalence at age 10 does not reach $25 \%$. These numbers suggest the existence of areas of high and intermediate endemicity in Brazil. According to serological surveys in Rio de Janeiro, hepatitis A seroprevalence is higher in low-income populations 8,9 . Risk of infection is associated with crowding and poor hygienic conditions in the domestic and social environment 10 .

Intermediate hepatitis A endemicity poses a public health paradox. The gradual improvement of hygiene reduces but does not eliminate hepatitis A transmission. Since sanitation improvement is not uniform, viral circulation remains high in some sectors, and part of the population reaches adulthood without being infected. While the infection is mild or asymptomatic in children (and can be mistaken for a flu infection), in adults it is more virulent. This implies that investment in sanitation may have an initially negative impact on hepatitis A epidemiology. Another important factor that should be considered when studying hepatitis A dynamics is that seasonal variation in the infection rate is strongly associated with the rainfall pattern 11 .

Several studies on hepatitis A epidemiology show that more research is needed on infection dynamics in order to establish more efficient vaccination programs 4,11 . In this study, we developed a mathematical model to describe the dynamics of hepatitis A transmission and evaluated it considering different levels of exposure to the disease. The modeling approach consists of developing a mathematical description of the sequence of events related to transmission and subsequent simulation of the dynamics. Mathematical models are useful tools for testing hypotheses on the system 12 and design and control strategies, helping to define when, who, and how to vaccinate, for example 13 . Mathematical models of diseases transmitted by the fecal-oral route, like hepatitis A, cholera, and typhoid fever, have been developed in literature aimed at evaluating the cost-benefit of alternative control strategies, like sanitation versus vaccination of risk groups 14,15,16,17,18.

\section{Model}

The first set of simulations were performed with equations adapted from Brow \& Rothery 19. This is a simpler model that does not explicitly include the population growth and mortality rates. Since the model without demographics does not allow persistence, we opted for a more complex model, adapted from Deangelis \& Gross 20 (equation 1). This is the well-known SIR model, originally developed by Kermack \& McKendrick 21. The equations were numerically solved using the StellaTM software.

$$
\begin{aligned}
& \frac{d S(t)}{d t}=\mu N-m S(t)-c \beta I(t) S(t) \\
& \frac{d I(t)}{d t}=c \beta S(t) I(t)-(m+\gamma) I(t) \\
& \frac{d R(t)}{d t}=\gamma I(t)-m R(t)
\end{aligned}
$$

Individuals are classified in three categories, according to their history of contact with the virus. Susceptible individuals (S) are those at risk of infection. They have never experienced an HA infection and are not vaccinated (seronegative). Infected individuals (I) are those that are currently infected and capable of transmitting infection to others. Recovered individuals $(\mathrm{R})$ are those that experienced the infection in the past and currently are totally immune. Susceptible individuals acquire infection at rate $c \beta I(t): c$ is the number of potentially infective contacts that a susceptible person has per day; $\beta$ is the probability that a 
person will actually get an infection after a potentially infective contact. Once infected, the individual leaves class S to class I. Individuals recover from infection at rate $\left(\gamma=1 / 30\right.$ day $\left.^{-1}\right)$ (recovery rate is the inverse of the average infectious period) 22. Viral fecal excretion is detected from the incubation phase to early symptomatic phase of the disease, during approximately 10 days 23 .

Birth and death rates were parameterized using data from the Greater Rio de Janeiro Metropolitan Area, as measured in 2000 (Instituto Brasileiro de Geografia e Estatística. Censo Demográfico 2000. http:// www.ibge.gov.br). Demographic process is modeled in a simple way. $\mu \mathrm{N}$ new individuals are born in the population per day and enter into the susceptible class, where $\mu$ is the per capita birth rate and $\mathrm{N}$ is the number of individuals in the population. Individuals in any class die at rate $m$.

Struchiner et al. 8 estimated the incidence rate of hepatitis A in three localities in Rio de Janeiro, characterized by different access to sanitation facilities. They estimated incidence as a function of age by fitting a Weibull survival curve to age-specific seroprevalence data. Averaging through all ages, they found a force of infection (hazard rate) equal to 0.0001 year-1 $^{-1}$ $0.27 \mathrm{e}-6$ day $^{-1}$. These values are used to parameterize the infection rate in our model (Table 1). We also included the effect of vaccination, removing individuals from the $\mathrm{S}$ to the $\mathrm{R}$ class.

To evaluate the amount of sanitation required to prevent further spread of hepatitis A, we modified the model considering different assumptions for the functional relationship between sanitation and contact rate:

$$
\begin{aligned}
& \frac{d S(t)}{d t}=(1-v) \mu N-m S(t)-c(H) \beta I(t) S(t) \\
& \frac{d I(t)}{d t}=c(H) \beta S(t) I(t)-(m+\gamma) I(t) \\
& \frac{d R(t)}{d t}=v \gamma I(t)-m R(t)
\end{aligned}
$$

where $v$ is the proportion of individuals vaccinated and $\mathrm{H}$ is the sanitation level of the community. The function $c(H)$ describes the effect of sanitation on the contact rate. It is reasonable to assume that the number of infectious contacts decreases as sanitation increases. It is not clear, however, which function should be used to model the relationship between contact rate and sanitation level. Here, we used three alternative functions (Figure 1), where $c_{\max }$ is the maximum contact rate and alphas are constants:

$$
\begin{aligned}
& c(H)=c_{\max }-\alpha_{1} H \\
& c(H)=c_{\max } e^{-\alpha_{2} H} \\
& c(H)=\frac{c_{\max }}{1+e^{\alpha_{3}\left(H-H_{50}\right)}}
\end{aligned}
$$

The linear function (equation 3) predicts that contact is reduced proportionally to the improvement of sanitation conditions. This is reasonable, if contact with fellow household members is the main mode of transmission. The exponential function (equation 4) says that a small improvement in hygiene causes

\begin{tabular}{|c|c|c|}
\hline Simulation & Infection rates (day $\left.{ }^{-1}\right)$ & Mortality rates $\left(\right.$ day $\left.^{-1}\right)$ \\
\hline 1 & $1.05 e-3$ & $8 e-6$ \\
\hline 2 & $1 e-3$ & $8 e-6$ \\
\hline 3 & $1.7 e-4$ & $5 e-7$ \\
\hline 4 & $4.7 e-5$ & $1.5 e-4$ \\
\hline 5 & $5.2 e-5$ & $1.5 e-4$ \\
\hline 6 & $5.2 e-5$ & $3.3 e-7$ \\
\hline 7 & $6.3 e-5$ & $3.3 e-7$ \\
\hline 8 & $5.8 e-5$ & $8.2 e-7$ \\
\hline 9 & $6.9 e-5$ & $5.4 e-6$ \\
\hline 10 & $8.3 e-5$ & $8.2 e-7$ \\
\hline
\end{tabular}
great impact on contact reduction. This may be reasonable in a setting where individuals share

Table 1

Parameters used in model simulations. Values chosen for infection rates are within the range of values estimated by Struchiner et al. 8 for microregions in Rio de Janeiro, Brazil, birth rates $\left(\right.$ day $\left.^{-1}\right)$ were 5.3 e -5 . 


\section{Figure 1}

Hepatitis A seroprevalence (P) as a function of the infection rate (cb)

Curve derived from model 2, equation 5 .

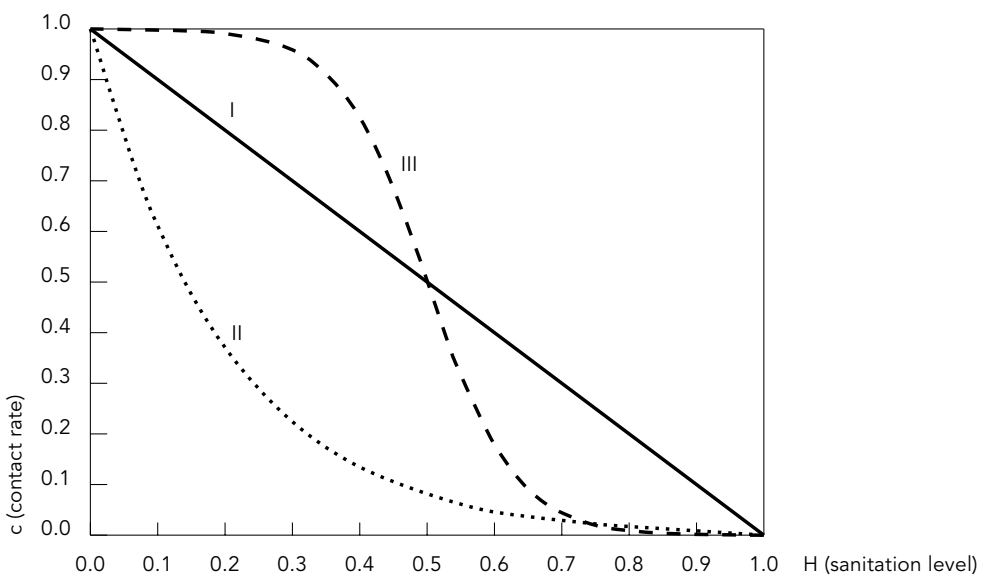

the same source of contamination. The third option is a sigmoidal curve (equation 5), applicable to a situation where sanitation has a small effect when low and its effect increases as it is expanded.

\section{Results}

\section{Without intervention}

We begin by describing the temporal dynamics of hepatitis A, according to equation 1 . If enough time is given, the system reaches a positive equilibrium:

$$
\begin{aligned}
& S^{*}=\frac{m+\gamma}{c b} \\
& I^{*}=\frac{\mu N(t)}{m+\gamma}-\frac{m}{c b} \\
& R^{*}=N(t)-I^{*}-S^{*}
\end{aligned}
$$

In this equilibrium, the relationship between contact rate and HA seroprevalence is nonlinear (Figure 2). In a community with 1,000 individuals, $50 \%$ seroprevalence is expected when the contact rate of ca. 0.0002 (i.e., 2 contacts per person per 10 days).

When equation system (equation 1) is solved numerically for different values of infection rate (Table 1), two kinds of results are obtained: either infection persists at a low level in the community and no outbreaks are observed (after the initial transient) or a chain of outbreaks are expected before the infected population settles to its equilibrium (Figures 3 and 4 ). These results suggest that the communities represented by the values in Table 1 experience different levels of endemicity.

\section{With intervention}

The ultimate goal of a public health strategy is to change the transmission dynamics of a disease in such a way that if an infected individual arrives in a community, he will not trigger an epidemic. Mathematically, this means $\frac{d I}{d t}<0$.

For hepatitis A, intervention can act in two ways: reducing the number of susceptible individuals $(S)$ by vaccination; or reducing the rate of contact (c) by sanitation. From equation system 1 , we find that $\frac{d I}{d t}<0$ implies that

$$
c<\frac{m+\gamma}{\beta S}
$$

Model 2 introduces three possible expressions for the relationship between the contact rate and $H$, the proportion of individuals with access to adequate sanitation facilities. Using these functions, we can define the level of $H$ required to prevent HA outbreaks.

$$
H<\frac{1}{\alpha_{1}}\left(c_{\text {max }}-\frac{m+\gamma}{\beta S}\right)
$$

for the linear model

$$
H<\frac{1}{\alpha_{2}} \ln \left[\frac{m+\gamma}{c_{\max } \beta S}\right]
$$

for the exponential model

$$
H<\frac{1}{\alpha_{3}} \ln \left(\frac{c_{\max } \beta S}{m+\gamma}-1\right)+H_{50}
$$

for the sigmoidal model

\section{Discussion}

Our simulations suggest that the infection rates measured in Rio de Janeiro 8 are characteristic of high and low endemicity patterns. The impact of partial sanitation on these communities will depend on the functional relationship between sanitation and its effect on exposure to infection. If this relationship is linear, impact of sanitation is inversely related to 
Three candidates for the relationship between sanitation level (proportion of individuals with access to sanitation services) and contact rate with sources of infection. Curves I, II, and III correspond to equations 3,4 , and 5 , respectively.

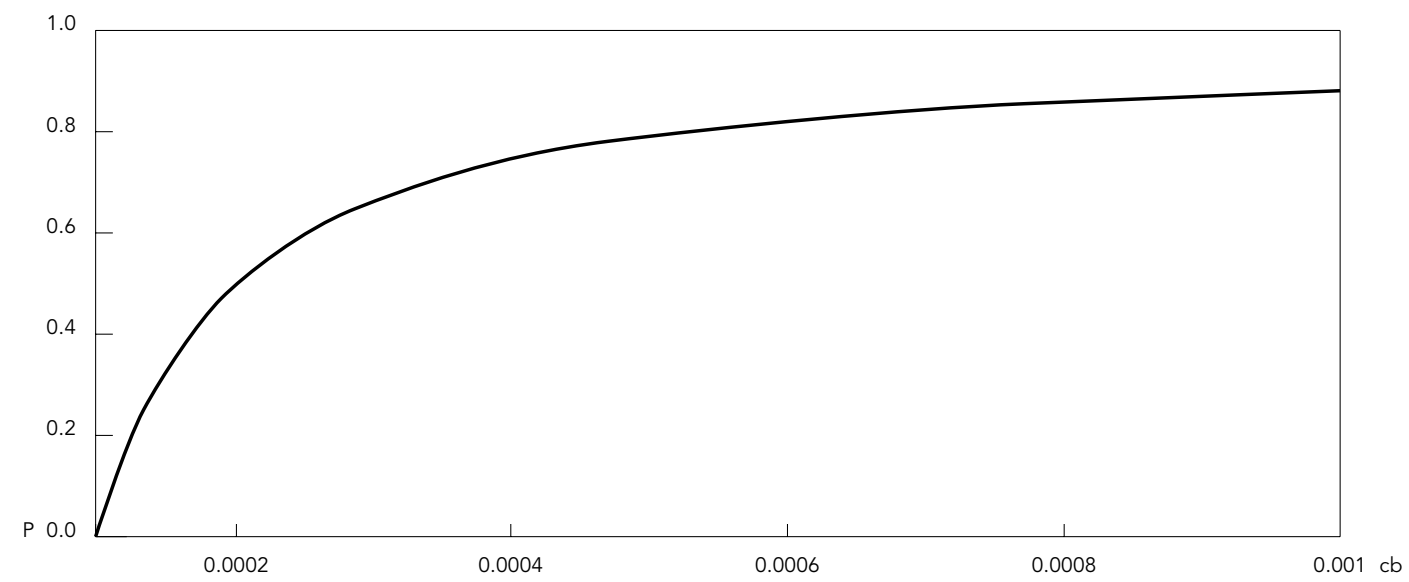

the number of susceptible individuals. That is, in a large population, partial sanitation would be hardly effective (it is either all or nothing). If this relationship is exponential, the impact of sanitation is inversely related to the $\log \mathrm{S}$. If this is the case, partial sanitation is expected to be a public health improvement. If the relationship is sigmoid, improvement is achieved only if sanitation crosses a threshold H50.

It is not clear which one of these functional relationships is more appropriate. They actually represent different situations that may take place at different places. The important point is that the impact of sanitation is sensitive to this function and more attention should be devoted to the understanding of the relationship between sanitation and contact.
Mathematical models are useful tools for the development of control strategies. In this work, we present a simple model for hepatitis A. This model is based on the classical SIR model. Further developments of this model should include spatial heterogeneity in contact rate and age-dependent force of infection. Although many seroepidemiological surveys have been conducted in Brazil as a whole and Rio de Janeiro, we still know very little about the population dynamics of hepatitis $A$ in Brazilian populations. To be able to build a more detailed model, further information is required on the patterns of contact in the population (stratified by age, social class, and locality), identification of main sources of disease transmission (direct contact $\mathrm{x}$ recreational contact $\mathrm{x}$ sanitation $\mathrm{x}$ water availability). 
Figure 3

Hepatitis A epidemiology of age class 1 to 4 .

Figure 3a

Microregion 9 (simulation 1).

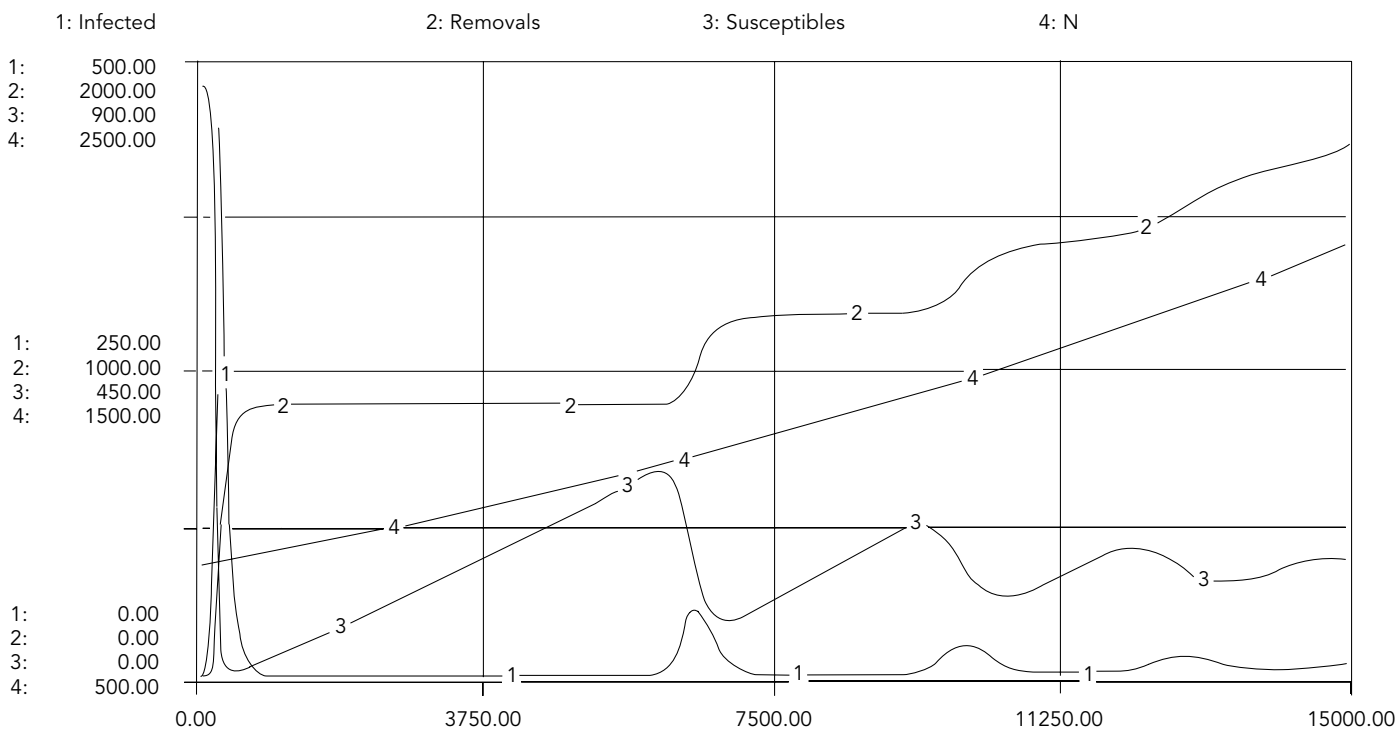

Figure $3 b$

Microregion 111 ages 1 to 4 (simulation 2).

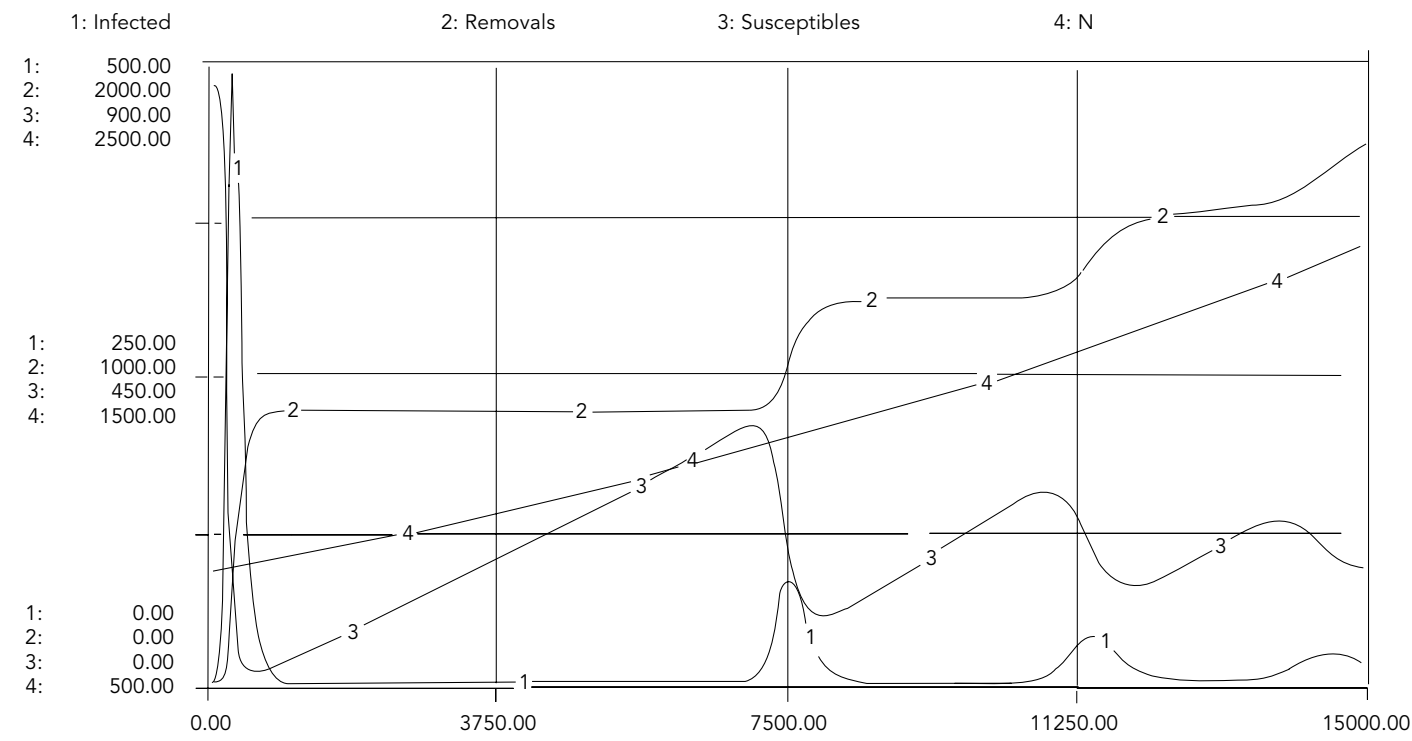

The population representatives are 1 : infected individuals: 2 : removals: 3 : susceptible individuals; and 4 : total population The $y$ axis represents numbers of individuals determined for each representative class of the population (1-4); these numbers are also written over the curves on the graphs, while the $\mathrm{x}$ axis represents the number of simulation days. 
MATHEMATICAL MODELS TO SIMULATE HEPATITIS A POPULATION DYNAMICS

1537

Figure 4

Hepatitis A epidemiology of ages class 15 to 19 .

Figure Ha

Microregion 9 (simulation 7).

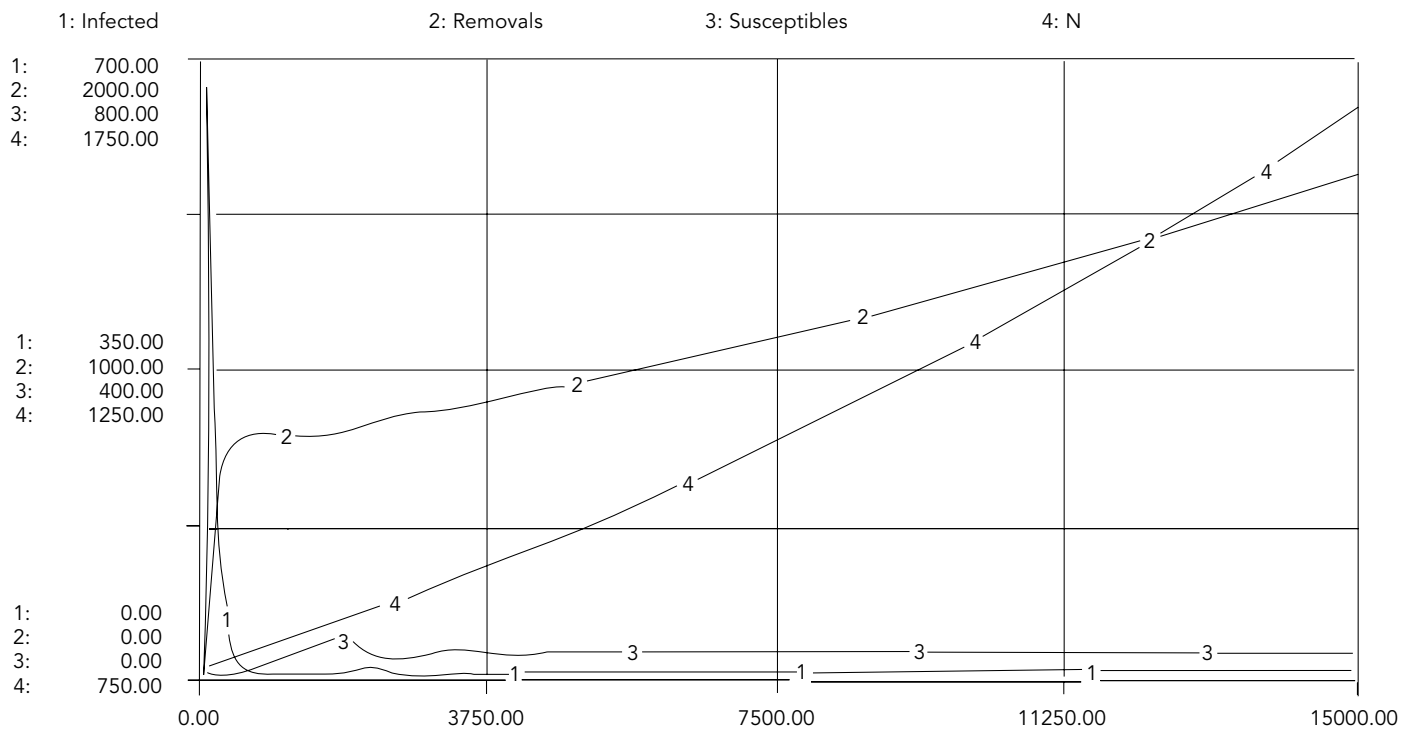

Figure $4 b$

Microregion 111 ages 15 to 19 (simulation 6).

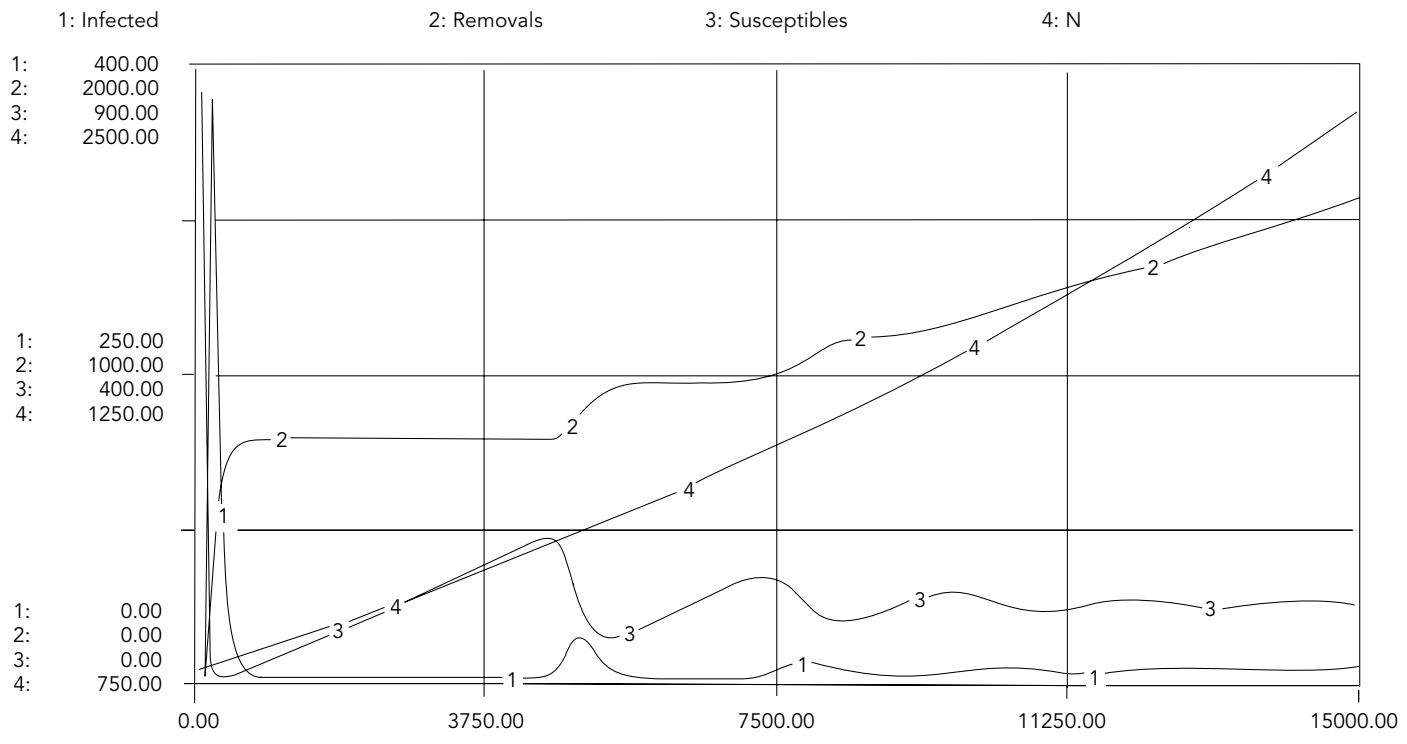

The population representatives are 1: infected individuals: 2: removals, 3: susceptible individuals; and 4: total population. The $y$ axis represents numbers of individuals determined for each representative class of the population (1-4); these numbers are also written over the curves on the graphs, while the $x$ axis represents the number of simulation days.

Cad. Saúde Pública, Rio de Janeiro, 21(5):1531-1539, set-out, 2005 


\section{Resumo}

Acesso heterogêneo a serviços sanitários é uma característica de comunidades brasileiras. Essa heterogeneidade promove diferentes níveis de exposição ao vírus da hepatite A, resultando em padrões variados de endemicidade: áreas com taxas altas de infecção possuem tendência para ocorrência de endemismo, enquanto taxas de infecção baixas mostram tendência para surtos. Neste trabalho, apresentamos um modelo matemático desenvolvido para estudar o efeito do risco variado de exposição na dinâmica epidemiológica da hepatite A. Equações diferenciais foram usadas para simular a dinâmica populacional e sua solução numérica obtida usando-se o programa Stella ${ }^{\circledR}$. O modelo usa parâmetros de infecção obtidos de estudos realizados na Região Metropolitana do Rio de Janeiro, em áreas com diferentes condições sanitárias. Simulações mostram que a amplitude observada de valores de taxa de infecção compreende dinâmicas de alta e baixa endemicidades de hepatite A. Observamos que a relação funcional entre saneamento e exposição à infecção é um componente importante do modelo. A análise do impacto do saneamento parcial requer uma maior compreensão desta relação.

Hepatite A; Modelos Matemáticos; Dinâmica Populacional

\section{Contributors}

M. A. Guimaraens conducted the programming and testing of simulations with the model using the StellaTM program and calculated the model's parameters using the literature, with the assistance of C. T. Codeço. Meanwhile C. T. Codeço performed the theoretical analysis of the model, including the intervention procedure. Both authors conducted the literature research and discussed the drafting of the introduction, formulation of the model, and final remarks.

\section{Acknowledgements}

This research was supported by the Oswaldo Cruz Foundation, Carlos Chagas Filho Rio de Janeiro State Research Support Foundation, grant number 15254501.

\section{References}

1. Szwarcwald CL, Leal MC, Castilho EA. Infant mortality rate in Brazil: Belgium-India or Bulgaria? Cad Saúde Pública 1997; 13:503-16.

2. Leal MC, Szwarcwald CL. Características da mortalidade neonatal no Estado do Rio de Janeiro na década de 80: uma visão espaço-temporal. Cad Saúde Pública 1997; 31:457-65.

3. Gust ID. Epidemiological patterns of hepatitis A in different parts of the world. Vaccine 1992; 10 Suppl 1:S56-8.

4. Tufenkeji H. Hepatitis A in Middle East and Africa. Vaccine 2000; 18:S65-7.

5. Tanaka J. Hepatitis A shifting epidemiology in Latin America. Vaccine 2000; 18:S57-60.

6. Vitral CL, Yoshida CFT, Lemos ERS, Teixeira CS, Gaspar AMC. Age-specific prevalence of antibodies to hepatitis A in children and adolescents from Rio de Janeiro, Brazil, 1978 and 1995. Mem Inst Oswaldo Cruz 1998; 93:1-5.

7. Clemens SA, Fonseca JC, Azevedo T, Cavalcanti A, Silveira TR, Castilho MC, et al. Soroprevalência para hepatite A e hepatite B em quatro centros no Brasil. Rev Soc Bras Med Trop 2000; 33:1-10.

8. Struchiner CJ, Almeida LM, Azevedo RS, Massad E. Hepatitis A incidence rate estimates from a pilot survey in Rio de Janeiro, Brazil. Int J Epidemiol 1999; 28:776-81.

9. Saback FL, Sabino RR, Carvalho SMF, Amorin LM, Gaspar AMC, Oliveira MLA, et al. Infection with Hepatitis A and TT viruses and socioeconomic status in Rio de Janeiro, Brazil. Scand J Infect Dis 2001; 33:121-5.

10. Almeida LM, Werneck GL, Cairncross S, Coeli CM, Costa MCE, Coletty PE. The epidemiology of hepatitis A in Rio de Janeiro: environmental and domestic risk factors. Epidemiol Infec 2001; 127 . 327-33.

11. Santos DMS, Souto FJD, Santos DRL, Vitral CL, Gaspar AMC. Seroepidemiological markers of enterically transmitted viral hepatitis A and $\mathrm{E}$ in individuals in a community located in the North area of Rio de Janeiro, RJ, Brazil. Mem Inst Oswaldo Cruz 2002; 97:637-40.

12. Guimaraens MA. The influence of environmental factors on the seasonal dynamics of Ulva sp. and Sargassum sp. in the Cabo Frio upwelling region of Brazil [Ph.D. Thesis]. Miami: University of Miami; 2000 .

13. Struchiner CJ, Brunet RC, Halloran ME, Massad E, Azevedo Neto RS. On the use of state-space models for the evaluation of health interventions. Journal of Biological Systems, 1995; 3:851-65.

14. Sundaresan TK, Grab B, Uemura K, Cvjetanovic B. Comparative epidemiological analysis of sanitation and immunization in the control of typhoid and cholera. Am J Public Health 1974; 64:910-2.

15. Cvjetanovic B, Grab B, Uemura K. Dynamics of acute bacterial diseases. Epidemiological models and their application in public health. Part II Epidemiological models of acute bacterial diseases. Bull World Health Organ 1978; 56 Suppl $1: 25-143$

16. Gay NJ. A model of long-term decline in the transmissibility of an infectious disease: implications 
for the incidence of hepatitis A. Int J Epidemiol 1996; 25:854-61

17. Ranchov GK. An epidemiometric model of viral hepatitis A and its use. Zh Mikrobiol Epidemiol Immunobiol 1996; 2:36-9.

18. Codeço CT. Endemic and epidemic dynamics of cholera: the role of the aquatic reservoir. BMC Infectious Diseases 2001; 1. http://www.biomedcentral.com/1471-2334/1/1.

19. Brown D, Rothery P. Models in biology: mathematics, statistics and computing. Chichester/ New York: John Wiley \& Sons; 1993.
20. Deangelis DL, Gross LJ. Individual-based models and approaches in ecology: populations, communities and ecosystems. New York: Chapman \& Hall; 1992.

21. Kermack WO, McKendrick. A contribution to the mathematical theory of epidemics. Proceedings Royal Statistics Society 1927; 115:700-21.

22. Plotkin AS, Orenstein WA. Vaccines. Philadelphia: W. B. Saunders; 1999.

23. Ciocca M. Clinical course and consequences of hepatitis A infection. Vaccine 2000; 18 Suppl 1:S71-4.

Submitted on 26/May/2003

Final version resubmitted on $22 / \mathrm{Jul} / 2004$

Approved on 21/Oct/2004 